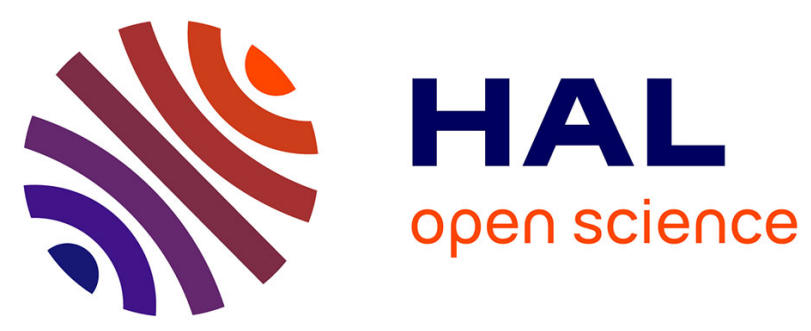

\title{
Cloud optical thickness and albedo retrievals from bidirectional reflectance measurements of POLDER instruments during ACE-2
}

Frédéric Parol, Jacques Descloitres, Yves Fouquart

\section{- To cite this version:}

Frédéric Parol, Jacques Descloitres, Yves Fouquart. Cloud optical thickness and albedo retrievals from bidirectional reflectance measurements of POLDER instruments during ACE-2. Tellus B Chemical and Physical Meteorology, 2000, 52 (2), pp.888-908. 10.1034/j.1600-0889.2000.00026.x . hal-00811540

\author{
HAL Id: hal-00811540 \\ https://hal.science/hal-00811540
}

Submitted on 10 Apr 2013

HAL is a multi-disciplinary open access archive for the deposit and dissemination of scientific research documents, whether they are published or not. The documents may come from teaching and research institutions in France or abroad, or from public or private research centers.
L'archive ouverte pluridisciplinaire HAL, est destinée au dépôt et à la diffusion de documents scientifiques de niveau recherche, publiés ou non, émanant des établissements d'enseignement et de recherche français ou étrangers, des laboratoires publics ou privés. 


\title{
Cloud optical thickness and albedo retrievals from bidirectional reflectance measurements of POLDER instruments during ACE-2
}

\author{
By FRÉDÉRIC PAROL*, JACQUES DESCLOITRES ${ }^{\ddagger}$ and YVES FOUQUART, Laboratoire \\ d'Optique Atmosphérique, Université des Sciences et Technologies de Lille, Villeneuve d'Ascq, France
}

(Manuscript received 2 February 1999; in final form 8 October 1999)

\begin{abstract}
The POLDER instrument is devoted to global observations of the solar radiation reflected by the Earth-atmosphere system. The airborne version of the instrument was operated during the ACE-2 experiment, more particularly as a component of the CLOUDYCOLUMN project of ACE-2 that was conducted in summer 1997 over the subtropical northeastern Atlantic ocean. CLOUDYCOLUMN is a coordinated project specifically dedicated to the study of the indirect effect of aerosols. In this context, the airborne POLDER was assigned to remote measurements of the cloud optical and radiative properties, namely the cloud optical thickness and the cloud albedo. This paper presents the retrievals of those 2 cloud parameters for 2 golden days of the campaign 26 June and 9 July 1997. Coincident spaceborne ADEOS-POLDER data from 2 orbits over the ACE-2 area on 26 June are also analyzed. 26 June corresponds to a pure air marine case and 9 July is a polluted air case. The multidirectional viewing capability of airborne POLDER is here demonstrated to be very useful to estimate the effective radius of cloud droplet that characterizes the observed stratocumulus clouds. A $12 \mu \mathrm{m}$ cloud droplet size distribution appears to be a suitable cloud droplet model in the pure marine cloud case study. For the polluted case the mean retrieved effective droplet radius is of the order of $6-10 \mu \mathrm{m}$. This only preliminary result can be interpreted as a confirmation of the indirect effect of aerosols. It is consistent with the significant increase in droplet concentration measured in polluted marine clouds compared to clean marine ones. Further investigations and comparisons to in-situ microphysical measurements are now needed.
\end{abstract}

\section{Introduction}

One of the major uncertainties in the determination of the climate sensitivity to human perturbations is the lack of understanding of the feedbacks associated with cloudiness changes and the diffi-

\footnotetext{
* Corresponding author address: Laboratoire d'Optique Atmosphérique, Université des Sciences et Technologies de Lille, UFR de Physique, Bât. P5, 59655 Villeneuve d'Ascq Cedex, France.

e-mail: frederic.parol@univ-lille1.fr

$\ddagger$ Present affiliation: University of Maryland, Department of Geography, College Park, USA.
}

culty for GCMs to correctly take into account cloud-radiation-climate interactions (Cess et al., 1990, 1996; Senior and Mitchell, 1993). The magnitude of the radiative cloud forcing is significant (see for instance Harrison et al., 1990) and a slight variation of cloud characteristics could have a strong influence on the evolution of the climate. Consequently, GCMs need a realistic representation of cloud properties and their effects on radiation budget at global and regional scale. Global observations are essential to achieve this objective.

Of course, the most comprehensive way to obtain global cloud observations is by means of spaceborne measurements. Nevertheless, airborne 
experiments and ground-based measurements remain essential to support the interpretation of satellite observations. Satellites can directly observe the spatial and temporal variabilities of clouds (Rossow and Schiffer, 1991) and also their effects on Earth's radiation budget at the top of the atmosphere (Ramanathan et al., 1989; Harrison et al., 1990). POLDER (POLarization and Directionality of the Earth's Reflectances) is a component of a series of new sensors that may provide key information to improve our knowledge of clouds, radiation and climate interactions (Buriez et al., 1997; Parol et al., 1999). The next generation of satellite instruments such as CERES (Cloud and the Earth's Radiant Energy System) (Wielicki and Barkstrom, 1991), MODIS (Moderate Resolution Imaging Spectrometer) (King et al., 1992), MISR (Multi-angle Imaging SpectroRadiometer) (Diner et al., 1998), POLDER will play a crucial rôle in helping to better understand clouds and their influence on the Earth's radiation balance.

One of the most significant cloud parameters used to determine the cloud-radiation interactions is the cloud optical thickness, which is directly related to the cloud droplet size distribution and the condensed water path (Fouquart et al., 1990). Projects as ISCCP (International Cloud Clymatology Project, Rossow and Schiffer, 1991) try to retrieve the cloud optical thickness from satellite measurements of visible radiance. They make the crude assumption of plane-parallel cloud layers with a prescribed cloud droplet size distribution. Thus the interpretation of satellite observations is based on both macrophysical and microphysical hypotheses. Numerous studies have derived the cloud optical thickness from remote sensing measurements using the plane-parallel approximation, but only few direct observations of cloud bidirectional reflectance have been compared to radiation fields calculated using the plane-parallel model (Davis and Cox, 1982; Stuhlmann et al., 1985; Baldwin and Coakley, 1991; Descloitres et al., 1995; Spinhirne et al., 1996; Descloitres et al., 1998).

This paper contains preliminary results related to such comparisons within the framework of the CLOUDYCOLUMN component (Brenguier et al., 2000) of the North Atlantic Regional Aerosol Characterisation Experiment (ACE-2). ACE-2 was the third experiment coordinated by the
International Global Atmospheric Chemistry Project (IGAC) that addresses atmospheric aerosol properties relevant to radiative forcing and climate. ACE-2 was conducted from 15 June to 31 July 1997 over the sub-tropical north-eastern Atlantic Ocean, with the base of operations in the Canary Islands (Raes et al., 2000; Verver et al., 2000). The present study has been conducted using data from both the spaceborne version of POLDER and the airborne simulator of the instrument. The multidirectional viewing capability of the POLDER instrument allows to observe a part of the Bidirectional Reflectance Distribution Function (BRDF) of any cloud scene. The BRDF is the angular distribution of radiances upcoming from the cloud layer. A direct integration of the BRDF over the hemispherical solid angle $2 \pi$ provides the true cloud albedo. However POLDER can instantaneously measure reflectances only in a limited number of view directions (up to $\sim 14$ ) while albedo calculation requires reflectances from all angles. An alternate method is applied that derives cloud optical thickness from measured bidirectional reflectance using the plane-parallel approximation. The plane-parallel model is then used again to derive the cloud albedo from that retrieved optical thickness. However the multidirectional measurement capability of POLDER offers a new perspective to this procedure. POLDER also enables to test the validity of the hypotheses (on cloud macrophysics and microphysics) used to determine the cloud optical thickness. This paper illustrates this new perspective. A feasibility study is presented that shows that the multiangular capability of the airborne POLDER can be useful to infer an approximate value of the cloud water drop size.

Both POLDER instruments and respective data are described in Section 2. The method for analyzing the angular dispersion of POLDER data is presented in Section 3. Sections 4 and 5 present the cloud properties, cloud amount, optical thickness, and albedo, derived from airborne POLDER data and coincident spaceborne ADEOSPOLDER data respectively. The original contribution of POLDER with respect to these products is emphasized. Airborne POLDER data acquired over the ACE- 2 region on 2 golden days of the campaign 26 June and 9 July 1997, and coincident spaceborne POLDER data from 2 ADEOS orbits over the Atlantic Ocean and Europe on 26 June 
1997 are analyzed. Results are summarized and discussed in Section 6.

\section{The POLDER instrument and data}

POLDER is a multispectral visible radiometer/ polarimeter devoted to observations of polarization and directionality of solar radiation reflected by the Earth's surface-atmosphere system. The instrument concept is simple and very similar to a camera. POLDER is composed of a 2-dimensional charge-coupled device (CCD) detector array, a rotating wheel carrying spectral and polarizing filters, and a wide field of view telecentric optics (see Deschamps et al., 1994, for further details).

\subsection{The satellite data}

The spaceborne version of POLDER is a CNES (the French Space Agency) instrument which flew aboard the Japanese ADEOS (ADvanced Earth Observing Satellite) polar orbiting platform between August 1996 and June 1997, including the first couple of weeks of the ACE-2 experiment. ADEOS is on a sun-synchronous orbit at an altitude of $797 \mathrm{~km}$. The along-track and crosstrack fields of view of POLDER extend up to $\pm 42^{\circ}$ and $\pm 52^{\circ}$ respectively. Thanks to POLDER's large swath width $(\sim 2200 \mathrm{~km})$, each point on the Earth is observed almost every day, and 4 days out of 5 near the equator. The CCD sensor array is composed of $242 \times 274$ pixels. The ground size of a POLDER pixel aboard ADEOS is $(6 \times 7) \mathrm{km}^{2}$ at nadir. As the ADEOS satellite passes over a scene, up to 14 successive measurements are made in 8 narrow spectral bands ranging from $0.44 \mu \mathrm{m}$ to $0.91 \mu \mathrm{m}$. The POLDER level- 1 products routinely processed by CNES consist of calibrated radiances and Stokes parameters projected on a reference equal-area global grid at $6.2 \mathrm{~km}$ resolution. There are no onboard calibration sources and the POLDER in-flight radiometric calibration is based on terrestrial targets (Hagolle et al., 1999).

One of the scientific objectives of the satellite mission relates to the Earth radiation budget and cloud characteristics (hereafter noted as "ERB \& clouds"): BRDF, cloud fraction, optical thickness, pressure, and phase (Buriez et al., 1997; Vanbauce et al., 1998; Parol et al., 1999). The level-2 and 3 "ERB \& clouds" products provide cloud properties averaged over $\sim 56 \times 56 \mathrm{~km}^{2}$ "super-pixel" regions $(\sim 9 \times 9$ pixels $)$. The spatial resolution of the super-pixel $\left(0.5^{\circ} \times 0.5^{\circ}\right.$ at the equator $)$ is convenient for comparisons to ISCCP products and to ERB instruments as ScaRaB (Scanner for the Earth Radiation Budget) (Kandel et al., 1994) and CERES (Wielicki and Barkstrom, 1991).

One example of $0.865 \mu \mathrm{m}$ level-1 radiance acquired by ADEOS-POLDER during the ACE-2 period is shown in Fig. 1. It is a composite image of $0.865 \mu \mathrm{m}$ reflectance measured along 2 successive ADEOS orbits on 26 June 1997. The image is made using the 8th observation for each pixel, which is practically close to the minimum view angle (POLDER observes a given target under up to 14 view angles). The 8th observation corresponds to view angles ranging from $\sim 5^{\circ}$ near the swath center to $\sim 65^{\circ}$ near the edges. The experimental ACE-2 domain approximately covers the image. In this figure clouds appear as bright pixels against a darker ocean background. In spite of the coarse spatial resolution of POLDER $(6.2 \mathrm{~km})$, the image clearly shows high variations of cloud structure ranging from scattered cumulus clouds to solid stratocumulus cloud layers.

\subsection{The airborne data}

During the ACE-2 campaign in Tenerife in June-July 1997, the airborne simulator of POLDER was operated aboard the German Dornier aircraft of the DLR (Deutsche Forschungsanstalt für Luft und Raumfahrt) and was flown over stratocumulus clouds. The field of view of the airborne instrument extends up to $\pm 52^{\circ}$ in the along-track direction and $\pm 42^{\circ}$ in the cross-track direction. Its CCD array is composed of $288 \times 242$ pixels. Considering the typical aircraft-cloud relative altitude, the field of view of the instrument corresponds to a scene of $\sim 4 \mathrm{~km} \times 3 \mathrm{~km}$ (approximately the size of one ADEOS-POLDER pixel). The spatial resolution of the airborne data is $\sim 15 \mathrm{~m}$, but it is degraded to $10 \times 10$ pixels, in order to reduce both the data flow and the measurement noise. The aircraft motion between 2 successive acquisitions of POLDER is approximately $500 \mathrm{~m}$. Angular deviations due to the pitch and roll of the aircraft are taken into account. The radiometer measures radi- 


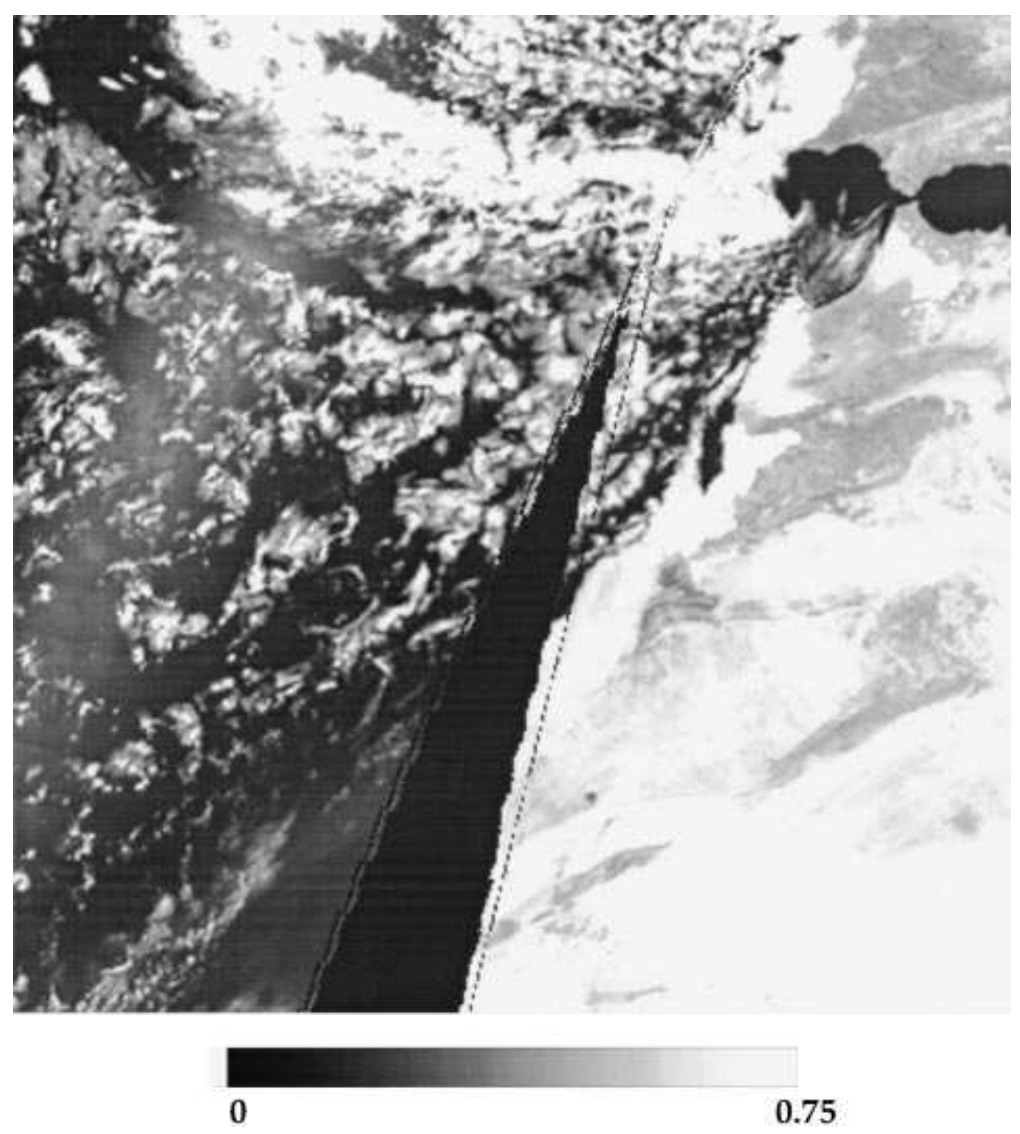

Fig. 1. ADEOS-POLDER composite image constructed from top of atmosphere reflectance at $0.865 \mu \mathrm{m}$ for a $\sim 2500 \mathrm{~km} \times 2500 \mathrm{~km}$ area of the Atlantic Ocean centered on $\left(28^{\circ} \mathrm{N}, 16^{\circ} \mathrm{W}\right)$ corresponding to the ACE-2 region on 26 June 1997 at 11:15 UTC (east orbit) and 12:50 UTC (west orbit). The top right of the image is Spain. Western Africa appears on the east orbit down to latitude $\sim 20^{\circ} \mathrm{N}$. The grey scale indicates the minimum and maximum values of observed bidirectional reflectance. The black dots near the inside boarders of these paths are missing data.

ances in 5 channels from $0.44 \mu \mathrm{m}$ to $0.91 \mu \mathrm{m}$. The POLDER calibration is performed in laboratory. The estimated accuracy in absolute reflectance is $5 \%$ and the pixel-to-pixel intercalibration accuracy is $0.5 \%$.

Similarly to the satellite version, the airborne POLDER can provide multidirectional reflectance measurements of any scene. A given target is seen under several view directions. The number of directions depends on the aircraft speed and the relative altitude of the aircraft with respect to the cloud top. Typically, it was 15 for stratocumulus clouds observed during ACE-2. Consequently, the same geographical target appears several times on a set of images but at different locations on the
CCD matrix (i.e., as many view angles). Fig. 2 illustrates this property of the instrument. It is easy to follow a given target (for instance, a hole in the cloud deck) on a series of successive images. In a cloud scene observed in a single high resolution POLDER image (which is in fact a BRDF limited to the solid angle corresponding to the instrument field of view), variations in bidirectional reflectances are due to both the anisotropy of the radiation coming from the scene and the horizontal variations in optical thickness from a cloud section to another within the instrument field of view (Descloitres et al., 1995). Nevertheless, as seen in Fig. 2, some parts of the observed cloud system are spatially uniform enough to make the

Tellus 52B (2000), 2 

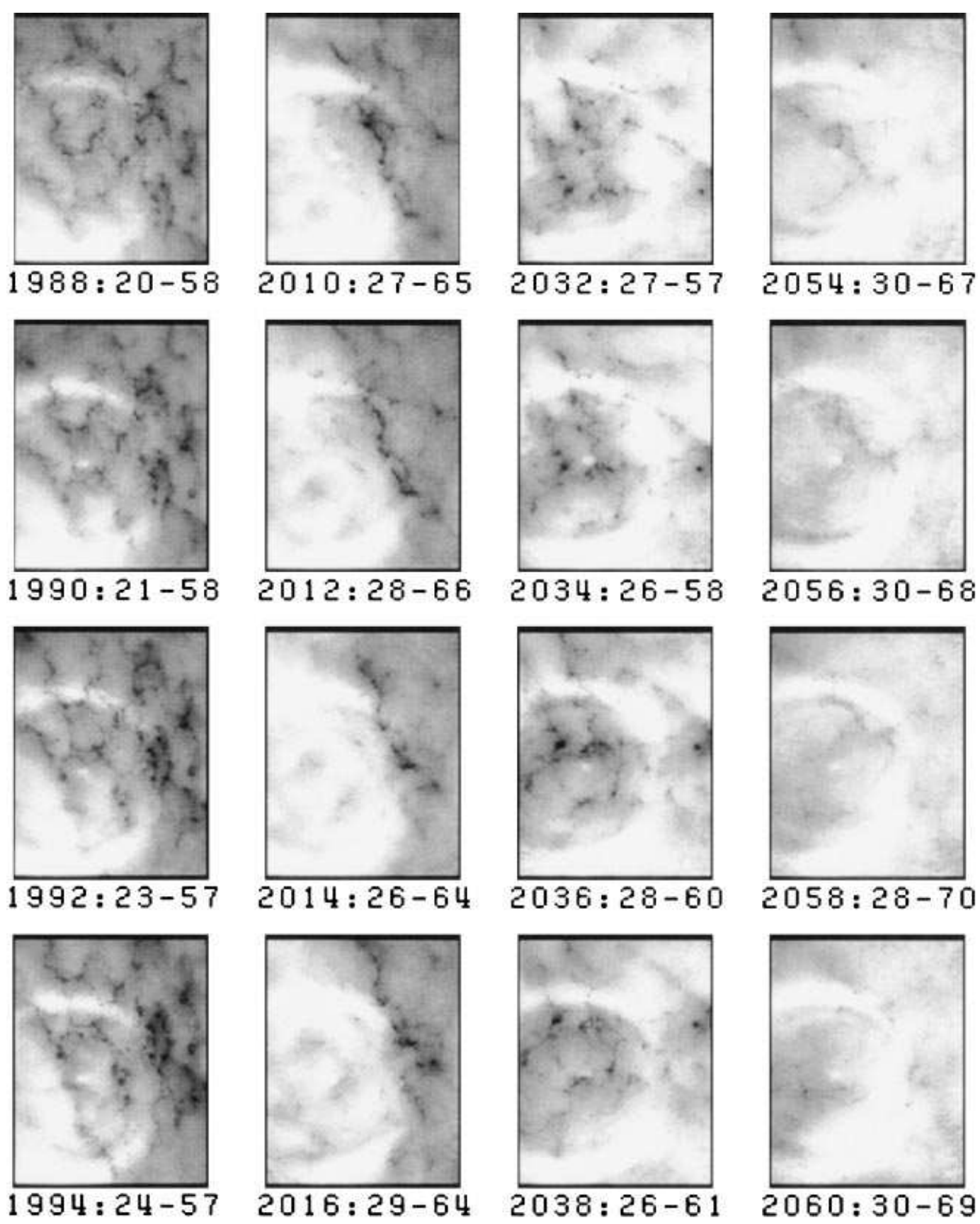

Fig. 2. Series of single $0.865 \mu \mathrm{m}$ reflectance images acquired by the airborne POLDER on 26 June 1997 approximately $1.5 \mathrm{~km}$ above stratocumulus clouds. The image number followed by the bidirectional reflectance range (in percent) corresponding to the grey scale are indicated at the bottom of each image. The grey scale in each panel is stretched from black to white to maximize contrast. 
anisotropy effects preponderant: the backscatter peak and the cloudbow $\left(\sim 140^{\circ}\right.$ scattering angle $)$ clearly appear on a lot of single images. Note that the cloudbow is a typical feature of clouds composed of liquid water drops.

\section{Methodology}

Measurements from both the spaceborne version of POLDER and the airborne simulator are used to estimate the angular dependency of cloud optical thickness and albedo retrieved under the plane-parallel approximation. A conventional procedure is applied to estimate the albedo for cloudy scenes. The upward radiance is used to determine the optical thickness, assuming the cloud scene homogeneous. The plane-parallel model is then used to derive the cloud albedo corresponding to the retrieved optical thickness.

In this procedure, the size distribution of cloud water droplets is prescribed and the cloud is assumed to be vertically uniform with respect to that distribution. In these conditions the optical thickness is the only cloud variable. Here, the horizontal dimensions of a cloud scene are $(\sim 150 \mathrm{~m})^{2}$ and $(6.2 \mathrm{~km})^{2}$ for the airborne and spaceborne POLDER, respectively. Since cloud scenes are assumed homogeneous (constant geometrical thickness) cloud optical thickness variations are proportional to variations in liquid water content.

\subsection{The airborne POLDER}

Following the methodology developed by Descloitres et al. (1995, 1996), cloud optical thickness and cloud albedo are estimated from the POLDER reflectance measurements at $0.865 \mu \mathrm{m}$, using the so-called "Independent Pixel Approximation" (Cahalan et al., 1994). For each cloud target $(\sim 150 \mathrm{~m})^{2}$, the bidirectional reflectance set (i.e., $\sim 15$ observations) is compared to the plane-parallel model, using the discrete ordinate method (Stamnes et al., 1988). The mean optical thickness of a cloud target is adjusted so that the mean reflectance over the $\sim 15$ different view angles equals the plane-parallel one (Descloitres et al., 1995). The corresponding planeparallel albedo is then derived from the mean retrieved optical thickness. In the plane-parallel model the surface ocean is modeled following Cox and Munk (1956). A prescribed droplet size distribution is used to model clouds.

Descloitres et al. (1995) applied such an approach to airborne POLDER data acquired during the ASTEX campaign above a stratocumulus cloud deck. They showed that, because of horizontal inhomogeneities, the clouds are not homogeneous plane-parallel layers over one single POLDER image, with a rms difference between the observed and the modeled reflectances of approximately $10 \%$. Nevertheless, the clouds compare favorably with a set of various independent plane-parallel layers. In that case the rms difference between observations and calculations is within 2-3\%. Descloitres et al. (1998) conclude that the Independent Pixel Approximation is valid for such a spatial resolution since the mean reflectance of a distribution of cloud targets is very close to the plane-parallel model.

Assuming the Independent Pixel Approximation, optical thickness and aldebo can be derived for each cloud target and for each view direction. The angular dispersion of the $\sim 15$ retrievals is due to the departure of the POLDER observations from the bidirectional reflectances calculated using the cloud model selected for the inversion. In this paper the angular dispersions are characterized for every target by the relative angular standard deviation defined as the angular standard deviation normalized to the mean value of the cloud property under consideration.

\subsection{The spaceborne POLDER}

The cloud optical thickness is estimated from the ADEOS-POLDER radiance measurements, using the Independent Pixel Approximation (Buriez et al., 1997). For each cloudy pixel $(6.2 \mathrm{~km})^{2}$, the bidirectional reflectance is compared to the plane-parallel model, using the discrete ordinate method (Stamnes et al., 1988). For each view angle, the cloud optical thickness is adjusted to make the plane-parallel bidirectional reflectance equal the reflectance observed in this direction. So the cloud optical thickness is determined for each view direction and each pixel. Moreover, in order to make easier the comparison to ISCCP climatology (Rossow and Schiffer, 1991), the cloud optical depth is calculated using the ISCCP liquid water cloud droplet model in the operational processing 
(Parol et al., 1999). It is a gamma distribution with an effective radius $r_{\mathrm{e}}=10 \mu \mathrm{m}$ and an effective variance of 0.15 (Hansen and Travis, 1974). The optical thickness is derived at 3 wavelengths $(0.443 \mu \mathrm{m}, 0.670 \mu \mathrm{m}$, and $0.865 \mu \mathrm{m})$ but finally only the value at $0.670 \mu \mathrm{m}$ is distributed in the level-2 "ERB \& clouds" products. The values at $0.443 \mu \mathrm{m}$ and $0.865 \mu \mathrm{m}$ are used as indicators of the reliability of the $0.670 \mu \mathrm{m}$ optical thickness. For each channel $(0.443 \mu \mathrm{m}, 0.670 \mu \mathrm{m}$, and $0.865 \mu \mathrm{m})$ and for each view angle the narrowband cloud albedo is derived from the retrieved optical thickness. The shortwave broadband albedo is determined for each view angle and estimated from the 3 narrow-band albedoes as explained by Buriez et al. (1997). These "directional" cloud properties are finally averaged at the super-pixel scale, i.e., on a $9 \times 9$ pixels area. As for the airborne POLDER retrievals, the angular dispersion is characterized for every super-pixel by the relative angular standard deviation of these $\sim 14$ values. Moreover the sub-super-pixel information is used to determine the relative spatial standard deviations for each viewing direction. In Section 5 the relative spatial standard deviation of the optical depth is computed for the 6th observation that corresponds to near-nadir viewing conditions for the central part of the orbit path.

In the operational retrieval the relation between the top-of-the-atmosphere reflectance and the cloud optical thickness is dependent on the surface reflectivity. For land pixels, the surface reflectance is obtained from surface parameters previously retrieved from POLDER observations in cloudfree conditions by the POLDER "Land surfaces" processing line (Leroy et al., 1997). For ocean pixels, the surface reflectance is calculated using Cox and Munk's (1956) model.

The plane-parallel approach used in the level-2 "ERB \& clouds" operational processing can lead to substantial errors when used to infer cloud optical thickness from actual satellite measurements (Loeb and Coakley, 1998). It may be also a major weakness in the assessment of the effects of clouds on radiation (Parol et al., 1994; Brogniez et al., 1992). Numerous theoretical studies have shown that 3-dimensional and plane-parallel clouds reflect radiation differently (Bréon, 1992; Kobayashi, 1993; Loeb et al., 1997). However, it is hardly possible to derive global cloud properties from space and take into account the effect of cloud morphology on radiation, because of the complexity of the cloud structures and their variability from one cloud type to another. All retrieved "ERB \& clouds" parameters are based on simple algorithms in order to be produced operationally. For instance, the cloud optical thickness is derived using the Independent Pixel Approximation. This does not take full advantage of the POLDER capability to observe the radiation field anisotropy. Nevertheless, the cloud parameters derived from POLDER at global scale are a first step to check the validity of the commonly used plane-parallel model. That is examined in Section 5.

\section{Airborne POLDER derived cloud properties}

During the ACE-2 CLOUDYCOLUMN closure experiment, the German Dornier was devoted to remote sensing above low-level clouds, providing observations at better resolution than satellite images. Coincident in-situ measurements were performed by the French Merlin IV aircraft from Météo-France. This is an opportunity to establish the relationship between microphysics measurements and horizontal variations of cloud properties captured by the POLDER and OVID (Barsch and Bakan, 1993) instruments aboard the Dornier (Brenguier et al., 2000). The aim of this section is to present some examples and analyses of the cloud optical thickness and spectral cloud albedo derived from POLDER reflectances at $0.865 \mu \mathrm{m}$ for 26 June and 9 July 1997. These 2 days have been selected as golden days of the ACE-2 CLOUDYCOLUMN field project.

\subsection{The 26 June 1997 case study}

During the ACE-2 mission 02 on 26 June 1997, the Dornier was flown over extended low-level clouds, while quasi-simultaneous in-situ microphysics measurements were performed aboard the Merlin (Brenguier et al., 2000). The stratocumulus was sampled along $30-\mathrm{km}$ legs. The visible and near-infrared channels (as at $0.865 \mu \mathrm{m}$ ) are primarily sensitive to the cloud optical thickness (see for instance Table 2 in Han et al., 1994). The retrieval of cloud optical thickness is thus almost not dependent on the drop size distribution. A gamma size distribution with an effective radius $r_{\mathrm{e}}=12 \mu \mathrm{m}$ 
and an effective variance of 0.15 is assumed (Hansen and Travis, 1974) to retrieve the optical thickness and derive the corresponding planeparallel albedo.

The cloud optical thickness and cloud albedo maps of the $\sim 30 \mathrm{~km} \times 3 \mathrm{~km}$ scenes, observed from the Dornier along one leg, are reported in Fig. 3. This leg corresponds to the southeast part of the square pattern performed on 26 June. It was sampled from 14:27 to 14:32 UTC. The color scale (from black to red) represents a range of optical thickness from 0 to 4.5 or range of albedo from 0 to approximately 0.28 . As expected for this flight mission, the cloud optical thickness values are low, ranging from 4.5 at the East point (point E) to less than 1.0 at the South point (point $\mathrm{S}$ ) of the leg. As expected for optically thin clouds, the albedo varies almost linearly against the optical depth (see for instance Stephens, 1978; Arking and Childs, 1985). The retrieved albedo decreases from 0.28 at $\mathrm{E}$ to approximately 0.05 at $\mathrm{S}$ (see Fig. $3 \mathrm{~b}$ ).

In order to check the sensitivity of cloud optical thickness and albedo retrievals to cloud microphysics, the retrieval was also performed using a cloud droplet effective radius of $6 \mu \mathrm{m}$. As expected, the retrieved values are only slightly lower and their spatial distribution (not presented here) is obviously very similar to Fig. 3. Indeed, computations show that the relationship between bidirectional reflectance, cloud optical thickness and albedo are almost not dependent on the droplet size (see Section 8).

More interestingly, as already explained in Section 3, the multidirectional capability of POLDER allows to quantify the angular dispersion of the cloud property retrievals. An example of relative angular standard deviation of cloud optical thickness is reported in Fig. 4 for an effective radius of $12 \mu \mathrm{m}$ and $6 \mu \mathrm{m}$.

On the maps in Fig. 4, a greater relative angular standard deviation indicates a less adequate cloud model. As shown in Fig. 4a, when inverting the POLDER reflectances assuming a $12 \mu \mathrm{m}$ effective radius, a large part of the leg presents relatively low values of relative angular standard deviations, i.e., less than 5-6\%. On the contrary, in Fig. 4 b the map shows a wide central band with very high values. As noted in Subsection 2.2 and shown in Fig. 2, this part of the POLDER images is sometimes observed in view conditions that correspond to strong anisotropic features like the backscatter maximum and the cloudbow $\left(\sim 140^{\circ}\right.$ scattering angle).

Fig. 5 compares observed and calculated variations of the cloud bidirectional reflectance against the view angle in the principal plane. The relative azimuth angle $\phi$ is measured with respect to the principal plane, so that the azimuthal coordinate of the sun (backscatter direction) is $\phi=0^{\circ}$. For all plots in the principal plane presented in this paper, positive zenith angles correspond to relative azimuth $\phi=0^{\circ}$, while negative correspond to $\phi=$ $180^{\circ}$. The plane-parallel simulations reported in Fig. 5 are made for 2 different sizes of cloud droplets, namely $6 \mu \mathrm{m}$ and $12 \mu \mathrm{m}$. The observed bidirectional reflectance curve corresponds to the average of 100 consecutive images along the leg under investigation. As given by Descloitres et al. (1995), this procedure removes the noise due to cloud heterogeneity across the POLDER CCD array. The observed peak located around view zenith angle $-20^{\circ}$ corresponds to the cloudbow (scattering angle $\sim 140^{\circ}$ ) and the second one more intense observed at view zenith angle $20^{\circ}$ in our case is the backscattered radiation (scattering angle $180^{\circ}$ ). As illustrated in this figure, the angular distribution of the simulated bidirectional reflectance is highly sensitive to the cloud microphysics in the observable domain of scattering angles. In the cloud optical thickness retrieval from POLDER measurements, the optical thickness of the plane-parallel model is adjusted to make the modeled reflectance match the average observed reflectance ( 0.182 for the present case). However, the angular distribution of the planeparallel bidirectional reflectance may still be very different from the observed one. The smoothness of the angular distribution depends on the cloud droplet size. The smaller the droplet size, the broader the peaks. In addition, the relative amplitude of the 2 peaks is also highly sensitive to the droplet size. The relative angular standard deviation of the retrieved cloud optical thickness (and of the retrieved cloud albedo) can significantly increase if the selected cloud droplet model is inadequate (Fig. 4).

In Fig. 6, 2 cloud droplet models were used to retrieve the cloud optical thickness from reflectance measurements in the solar plane. This angular optical thickness is compared to the one retrieved using the whole field-of-view of the instrument $\left(2.56\right.$ for $r_{\mathrm{e}}=6 \mu \mathrm{m}$ and 2.97 for $r_{\mathrm{e}}=$ 

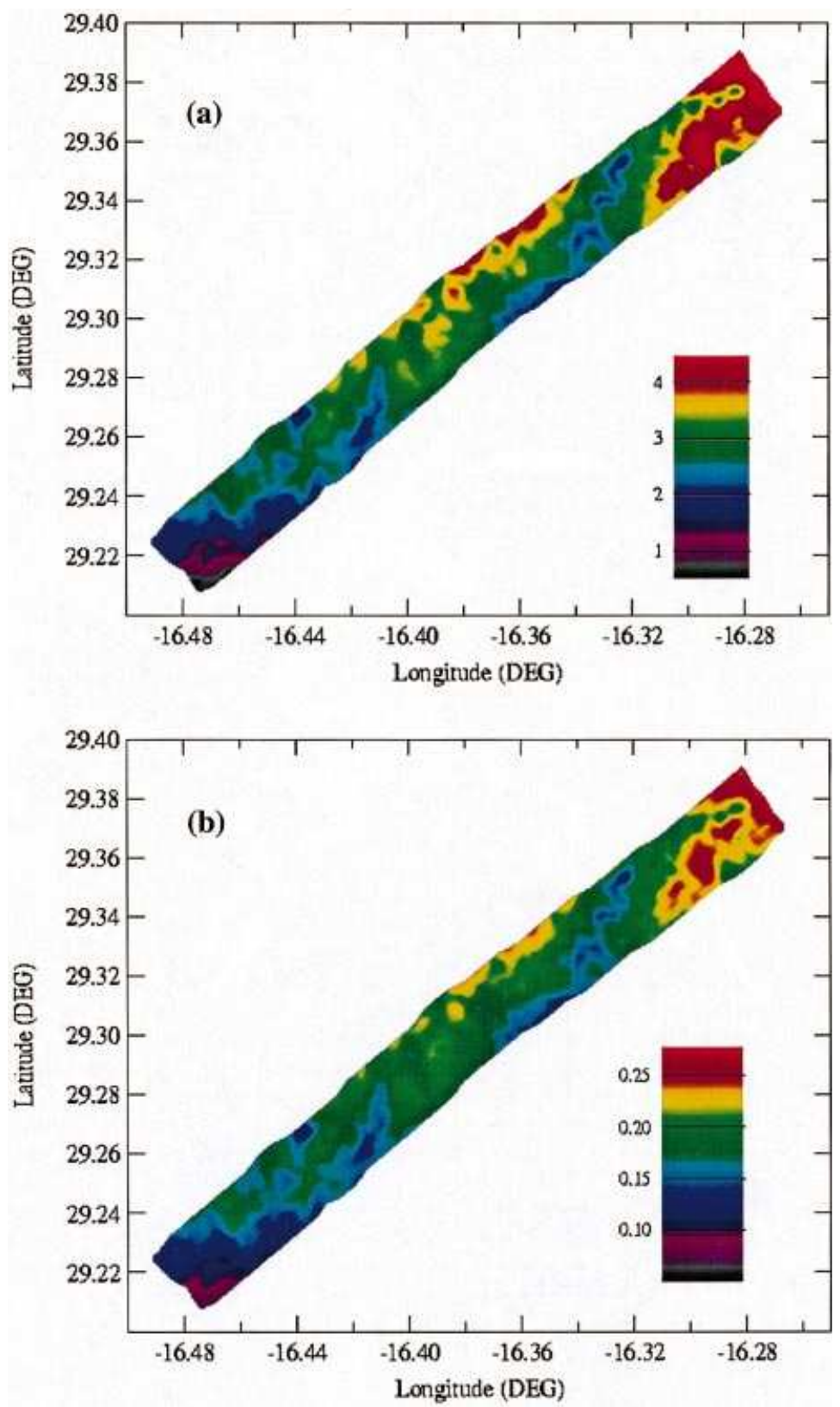

Fig. 3. (a) Cloud optical thickness and (b) cloud albedo maps established from airborne POLDER measurements acquired on 26 June 1997 between 14:27 and 14:32 UTC. The effective radius of droplet size distribution is $12 \mu \mathrm{m}$. 

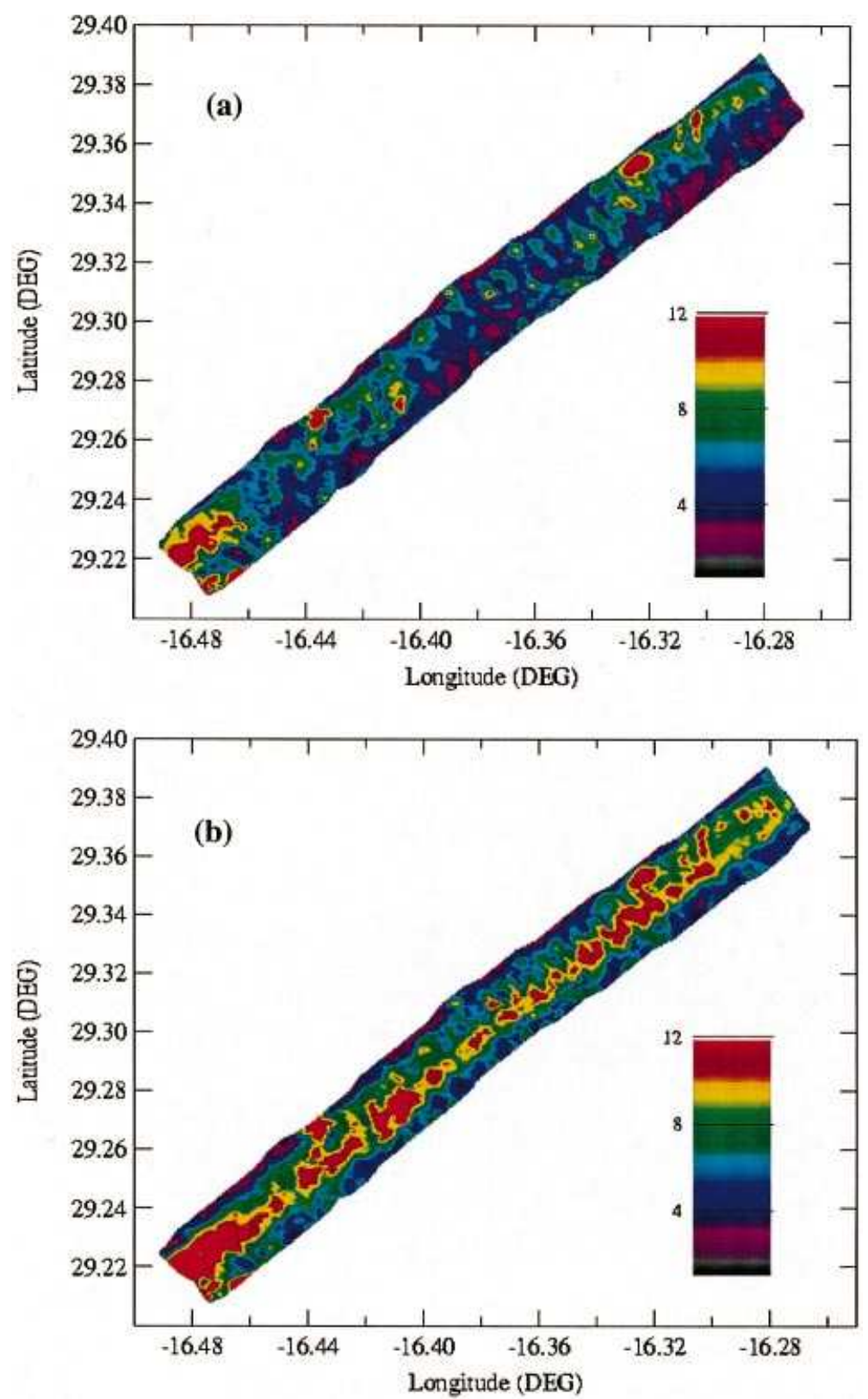

Fig. 4. Relative angular standard deviation (in \%) of cloud optical thickness maps established from airborne POLDER measurements acquired on 26 June 1997 between 14:27 and 14:32 UTC. The effective radius of droplet size distribution is (a) $12 \mu \mathrm{m}$ and (b) $6 \mu \mathrm{m}$. 


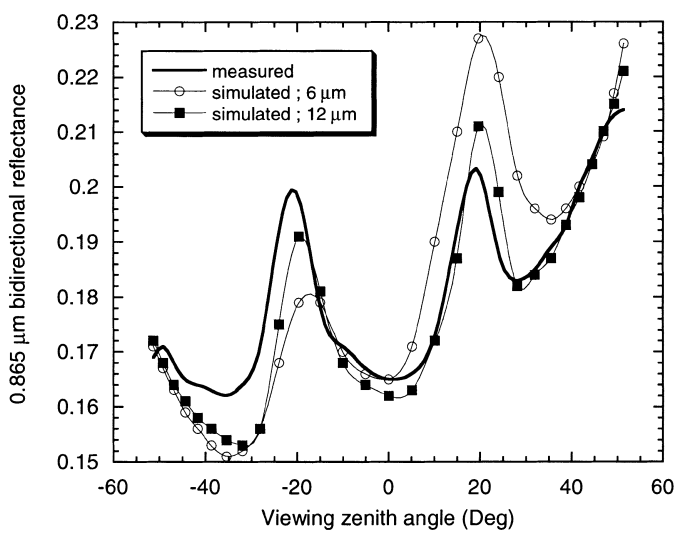

Fig. 5. Comparison between the measured cloud bidirectional reflectance (in the solar plane) and theoretical ones obtained using droplet effective radius of $6 \mu \mathrm{m}$ or $12 \mu \mathrm{m}$. The simulations correspond to the 26 June 1997 case study. The surface albedo is fixed to 0.05 . The mean retrieved cloud optical depth is equal to 2.56 and 2.97 , for $r_{\mathrm{e}}=6 \mu \mathrm{m}$ and $r_{\mathrm{e}}=12 \mu \mathrm{m}$, respectively.

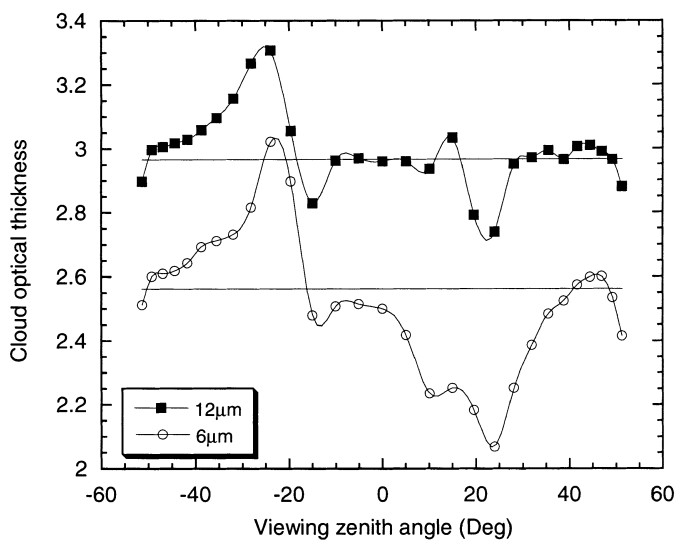

Fig. 6. Cross-sections along the principal plane of the retrieved cloud optical thickness using 2 droplet effective radius of $6 \mu \mathrm{m}$ or $12 \mu \mathrm{m}$. The simulations correspond to the 26 June 1997 case study. The surface albedo is fixed to 0.05 . The mean cloud optical depths retrieved using the whole field-of-view of POLDER (solid lines) are equal to 2.56 and 2.97 , for $r_{\mathrm{e}}=6 \mu \mathrm{m}$ and $r_{\mathrm{e}}=12 \mu \mathrm{m}$, respectively.

$12 \mu \mathrm{m})$. This clearly illustrates the error that is made when the cloud optical thickness is retrieved from one single view angle. According to Fig. 5, the cloud optical thickness is notably underestimated in the backscatter direction and overestimated in the cloudbow region. The angular variability of the optical thickness is lower for $r_{\mathrm{e}}=12 \mu \mathrm{m}$ than for $r_{\mathrm{e}}=6 \mu \mathrm{m}$. The $12 \mu \mathrm{m}$ cloud droplet size distribution is a more suitable cloud model in this case study.

\subsection{The 9 July 1997 case study}

During the ACE-2 mission 06 on 9 July 1997, the Dornier was flown over extended stratocumulus clouds thicker than during mission 02 . The cloud deck was sampled along $50-\mathrm{km}$ legs. In this section we analyze a leg corresponding to the Northwest part of the square pattern performed on 9 July 1997 (Brenguier et al., 2000). It was sampled between 14:39 and 14:48 UTC. The procedure presented in the previous section was applied to this case. The best agreement between observed and simulated bidirectional reflectance is obtained for droplet size distributions with an effective radius ranging from $6 \mu \mathrm{m}$ to $10 \mu \mathrm{m}$. As shown in Fig. 7, these 2 models minimize the angular variability of the retrieved cloud optical thickness. As noted previously and displayed in this figure, the mean retrieved cloud optical thickness is almost not dependent on the model drop size since the mean values are 7.02 and 7.68 for $r_{\mathrm{e}}=6 \mu \mathrm{m}$ and $r_{\mathrm{e}}=10 \mu \mathrm{m}$, respectively.

The cloud optical thickness and cloud albedo

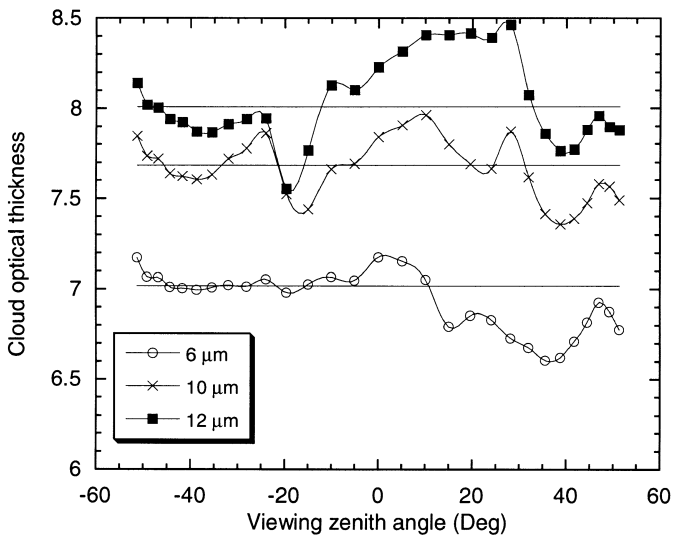

Fig. 7. Cross-sections along the principal plane of the retrieved cloud optical thickness using 3 droplet effective radius of $6 \mu \mathrm{m}, 10 \mu \mathrm{m}$, and $12 \mu \mathrm{m}$. The simulations correspond to the 9 July 1997 case study. The surface albedo is fixed to 0.05 . The mean cloud optical depths retrieved using the whole field-of-view of POLDER (solid lines) are equal to 7.02, 7.68, and 8.01, for $r_{\mathrm{e}}=6 \mu \mathrm{m}, r_{\mathrm{e}}=$ $10 \mu \mathrm{m}$, and $r_{\mathrm{e}}=12 \mu \mathrm{m}$, respectively. 
maps of the $\sim 50 \mathrm{~km} \times 3 \mathrm{~km}$ scenes are derived from POLDER reflectance, assuming $r_{\mathrm{e}}=10 \mu \mathrm{m}$, and are reported in Fig. 8. The color scale (from black to red) represents a range of optical thickness from 0 to 18.0 or a range of albedo from 0 to approximately 0.75 . The optical thickness and albedo values are definitely greater than the values derived on 26 June 1997. The spatial distribution of cloud properties also appears much more heterogeneous than in the previous case.
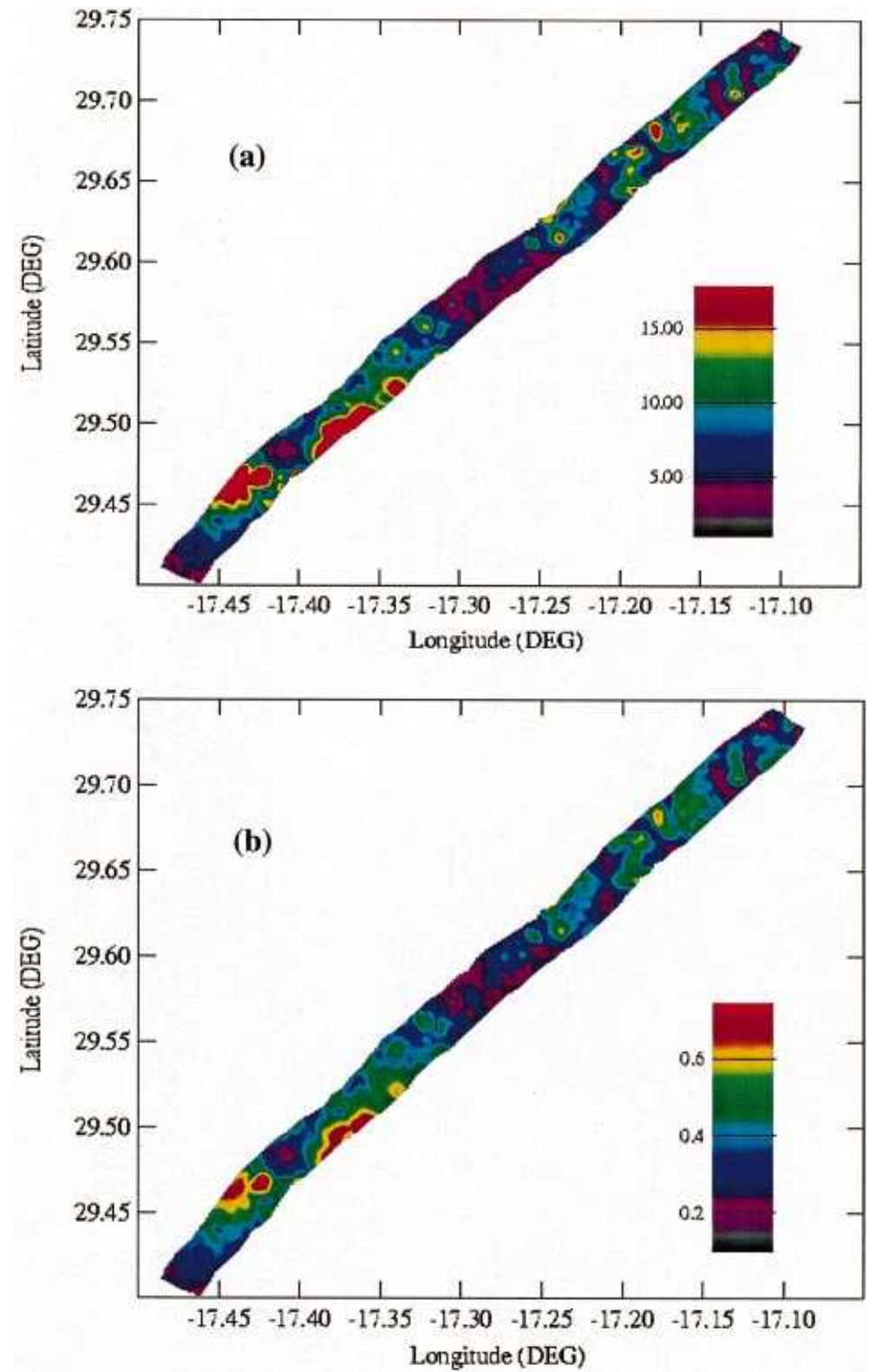

Fig. 8. (a) Cloud optical thickness and (b) cloud albedo maps established from airborne POLDER measurements acquired on 9 July 1997 between 14:39 and 14:48 UTC. The effective radius of droplet size distribution is $10 \mu \mathrm{m}$.

Tellus 52B (2000), 2 
The overall relative angular standard deviation (not reported here) of the retrieved parameters is low (less than 5-6\%) for most of the leg. Low values of relative angular standard deviations are mostly found where the cloud optical depth and albedo are moderate. The deviation is more significant where the cloud is more heterogeneous with sharp variations of optical thickness. In those particular cases the cloud deck locally departs from the plane-parallel approximation, regardless of the droplet size.

\subsection{Discussion}

The angular dispersion of cloud optical thickness derived from multidirectional measurements of cloud radiances with POLDER on board the Dornier are used to estimate the effective radius of droplets. Each cloud target $(\sim 150 \mathrm{~m})^{2}$ is assumed homogeneous and vertically uniform with respect to the droplet size distribution. This procedure is based on the Independent Pixel Approximation and was validated by Descloitres et al. $(1995,1998)$. This enables to model the cloud heterogeneity at spatial scales of a few hundred meters (Figs. 3, 8).

An important issue is the assumption of vertical homogeneity. Stratocumulus clouds have significant vertical heterogeneity and many authors have shown that liquid water content and effective radius increase with altitude from cloud base to cloud top (Slingo et al., 1982; Stephens and Platt, 1987). More recently Brenguier et al. (1999) have shown the adiabatic stratified plane-parallel model is more realistic than the vertically uniform planeparallel model to parameterize the stratocumulus cloud optical thickness in global climate models (GCM). Brenguier et al. (2000) validate the adiabatic stratified plane-parallel model from in situ and remote sensing measurements collected during the ACE-2 CLOUDYCOLUMN field campaign. This result is important for the simulation of cloud effects in GCMs that include cloud geometrical thickness as a diagnostic parameter. Nonetheless, these results do not make our procedure questionable. Simulations by Nakajima and King (1990) suggest that the derived vertically uniform optical thickness differs from the true optical thickness by no more than $3 \%$ for typical vertically inhomogeneous conditions. Calculations performed by Brenguier et al. (1999) confirm this result.
Moreover, Pawlowska et al. (1999) show that the vertically uniform optical thickness derived from POLDER compares well with the microphysical measurements. This optical thickness is used to validate the parameterization based on the adiabatic vertical profile of the microphysics proposed by Brenguier et al. (1999).

The other issue is the derivation of droplet effective radius from remote sensing data. Several authors have investigated methods based on multiwavelength shortwave measurements to simultaneously retrieve the cloud optical thickness and the effective radius (Nakajima and King, 1990; Nakajima et al., 1991; Han et al., 1994; Brenguier et al., 1999). Sensitivity studies on the effect of vertical heterogeneity on the retrieval of effective radius suggest that this radius is typically $80-100 \%$ of the radius at cloud top (Nakajima and King, 1990; Brenguier et al., 1999). The present feasibility study is mainly based on the angular dependence of the reflected radiance (position and intensity of the cloudbow and backscatter peak; see Fig. 4). These features are mainly driven by single scattering (Hansen and Travis, 1974). Consequently the proposed approach is a retrieval of the upper few units of cloud optical thickness located at the cloud top.

The present results show that a $12 \mu \mathrm{m}$ effective radius is a suitable cloud droplet size model in the pure marine case study (26 June) while an effective radius of $6 \mu \mathrm{m}$ to $10 \mu \mathrm{m}$ is more suitable to the polluted case ( 9 July). Assuming no variations of cloud morphological aspect, a verification of the indirect effect of aerosols (the so-called Twomey effect) may be reduced to a verification of the decrease of droplets size via an increase of anthropogenic aerosol concentration. In that sense, these preliminary results can be interpreted as a confirmation of the indirect effect of aerosols. They are consistent with the extended analysis presented by Brenguier et al. (2000; see their Fig. 5) who show a first experimental evidence of the indirect effect at the scale of a cloud system.

\section{ADEOS-POLDER daily retrievals: the 26 June 1997 case study}

This section presents the ADEOS-POLDER data acquired on 26 June 1997 along 2 ADEOS orbits over the Atlantic Ocean and Europe. The 
main results (cloud amount, cloud optical thickness and shortwave broadband albedo) of the "ERB \& clouds" operational algorithm are discussed in details for a $\sim 2500 \mathrm{~km} \times 2500 \mathrm{~km}$ area corresponding to the ACE-2 region (Fig. 1). The original contribution of POLDER regarding these properties is emphasized.

In the operational "ERB \& clouds" processing, the cloud detection algorithm is a threshold method applying several sequential tests for the presence of clouds. Parol et al. (1999) argue about the adjustments of the different tests and favorably compare the POLDER cloud detection algorithm to the Dynamic Clustering Method applied to Meteosat data (Sèze and Desbois, 1987). The tests are applied to each individual pixel $(6.2 \mathrm{~km})$ and for every view direction. The cloud cover is determined direction by direction and, and the cloudiness is then averaged (Buriez et al., 1997).

Fig. 9 shows the cloud cover, the cloud optical thickness and the shortwave broadband albedo (see Subsection 3.2) for the ACE-2 region of interest. The cloud cover presented in Fig. 9a is obtained by spatial and angular averaging for each POLDER super-pixel $(\sim 9 \times 9$ pixels $)$. Similarly, the cloud optical thickness shown in Fig. $9 \mathrm{~b}$ corresponds to a spatial and angular average on the cloudy pixels within the super-pixel. All large cloud structures associated with the main climate processes are easily identified and their location is consistent with what we would expect for this time of year: for instance the inter-tropical convergence zone (ITCZ) along the $10^{\circ} \mathrm{N}$ parallel and the large clear-sky area over the desert of Sahara. The spatial distribution of cloud cover is mainly linked to the meteorological synoptic situation at this date. In particular, a cyclone persisted over Western Europe at the end of June (Verver et al., 2000). High cloudiness is observed off the coast of Spain over the Atlantic Ocean.

The spatial distribution of cloud optical thickness and shortwave albedo is consistent with the observed structures of cloud cover and their expected regional reflective characteristics. There are some high values all along the ITCZ with some very bright cloud cells. High values also appear in mid-latitude depression areas (off Spain).

More extended than airborne POLDER observations, the ADEOS-POLDER images show that low broken stratocumulus clouds covered the ACE-2 area on 26 June 1997. The cloud cover and cloud optical thickness maps (Fig. 9a,b) confirm this synoptic situation. These cloud properties are highly variable in space. The proportion of partly cloudy pixels that can correspond to cumulus, scattered stratocumulus or cloud edges is important. Note that "partly cloudy" has not the same meaning for POLDER as for a usual radiometer. In the case of the POLDER cloud detection algorithm, some pixels can be labeled as cloudy for some directions and clear for others (Buriez et al., 1997; Parol et al., 1999). Over the ACE-2 region, the derived values of cloud optical depth and shortwave albedo are quite low. The cloud optical depth ranges from 1.0 to approximately 8.0 and the shortwave albedo is less than $\sim 0.25$ (see Fig. 9c). Because of 2 very different spatial scales $\left((56 \mathrm{~km})^{2}\right.$ in this case and $(\sim 150 \mathrm{~m})^{2}$ for the airborne POLDER) an exact comparison between these values and those obtained from the airborne data is not realistic. However, these values are consistent with low optical depths and spectral albedoes presented in Subsection 4.1.

These low values are associated to high values of spatial and angular dispersion of cloud optical depth. This is emphasized on Figs. 9d,e that respectively present the relative spatial and angular standard deviations of the optical thickness. As explained in Subsection 3.2, the cloud is assumed to be a plane-parallel layer composed of droplets with an effective radius of $10 \mu \mathrm{m}$ in the level-2 "ERB \& clouds" operational scheme (Buriez et al., 1997). Consequently, the relative angular standard deviations increase if this approximation is inadequate (Fig. 9e). Note that, in Figs. 9d,e, the color scale upper limits are very different. Generally, the spatial deviation is twice higher than the angular deviation.

A first reason for a high relative angular standard deviation is that the measured angular distribution can be very different from the plane-parallel cloud model depending on the cloud brokeness, because of cloud shape and mutual shadowing effects (Bréon, 1992; Loeb et al., 1997; Loeb and Coakley, 1998). Another reason is that the microphysical model is not suitable (Section 4). For instance, it is well known that cirrus cloud properties are very sensitive to ice crystal shape and orientation (Mishchenko et al., 1996). However, the study of ice clouds is far beyond the scope of ACE-2. So the rest of the analysis focuses on the derivation of liquid water cloud properties only. 

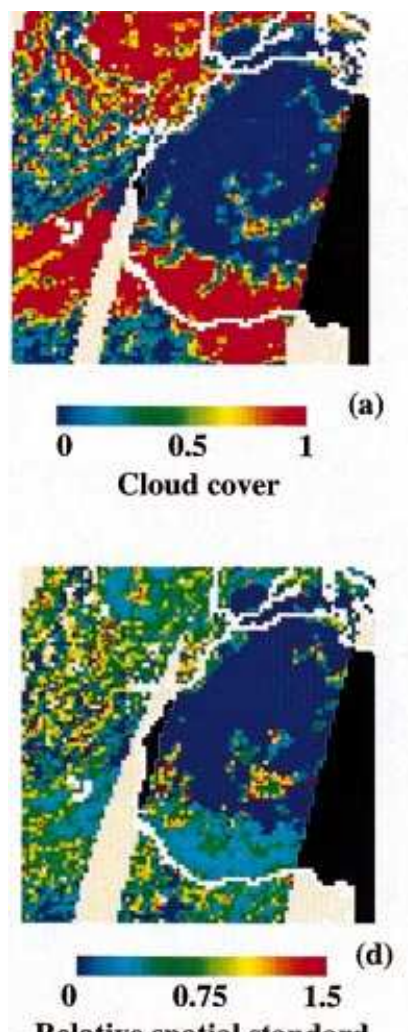

\section{Relative spatial standard} deviation

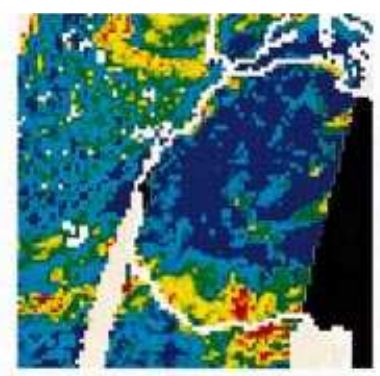

(b)

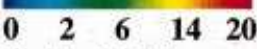

Optical thickness

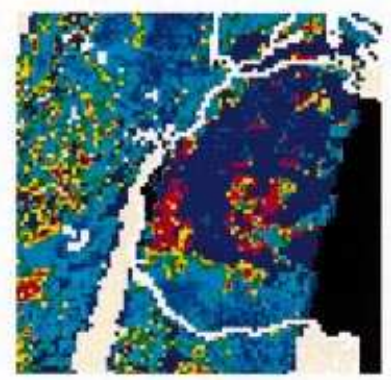

(e)

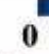

0.25

0.5

Relative angular standard deviation
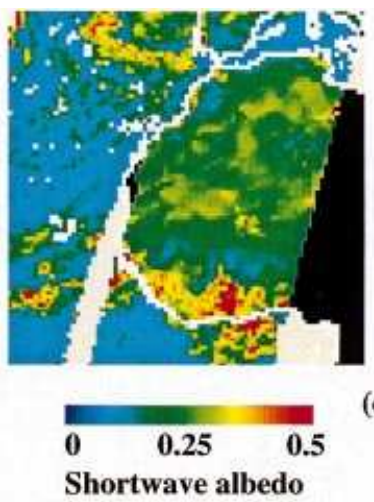

(c)

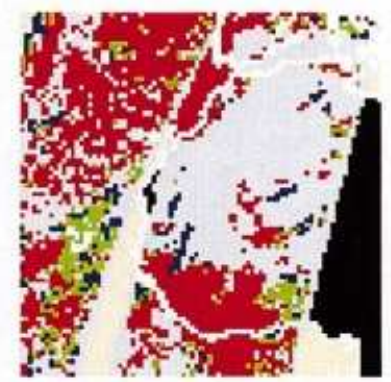

(f)

Thermodynamic phase index

Fig. 9. Image constructed from POLDER level-2 (a) cloud cover, (b) cloud optical thickness and (c) shortwave albedo derived for 26 June 1997 over the ACE-2 region. (d) and (e) are respectively constructed from relative spatial standard deviation and relative angular standard deviation of cloud optical thickness. (f) is the thermodynamic phase index (red is for liquid droplets, dark blue for ice crystals, green for mixed phase, and grey for "clear" and "not computed" (Parol et al., 1999).

A thermodynamic phase index (Fig. 9f) derived from polarization measurements at $0.865 \mu \mathrm{m}$ is used to identify the POLDER pixels composed of liquid water clouds (further details can be found in Parol et al., 1999). Fig. 10 presents the variability rates as a function of the cloud optical thickness only for these cloud pixels labeled "droplets". In order to assess the effect of brokeness on these curves, overcast situations are separated from the other ones. For the purpose of this analysis, a POLDER super-pixel is considered as overcast if the cloud fraction is greater than 0.95. Practically, overcast super-pixels are mainly located along the ITCZ and the southern part of the cyclone centered over Western Europe (Fig. 9a). The 2 sets of curves associated to the 2 cloud fraction cases are not significantly different. However, the magnitude of the standard deviations observed in overcast conditions is lower and the optical thickness is larger.

Figs. 10a,c confirm that large values of cloud optical thickness give moderate values of relative spatial standard deviation, while these get more scattered as the cloud optical depth gets small. In the case of broken cloudiness, small spatial standard deviation is always related to small optical thickness (Fig. 10a).

The relative angular standard deviation behaves differently (Figs. 10b,d). Low angular standard deviation is observed for all values of cloud optical 

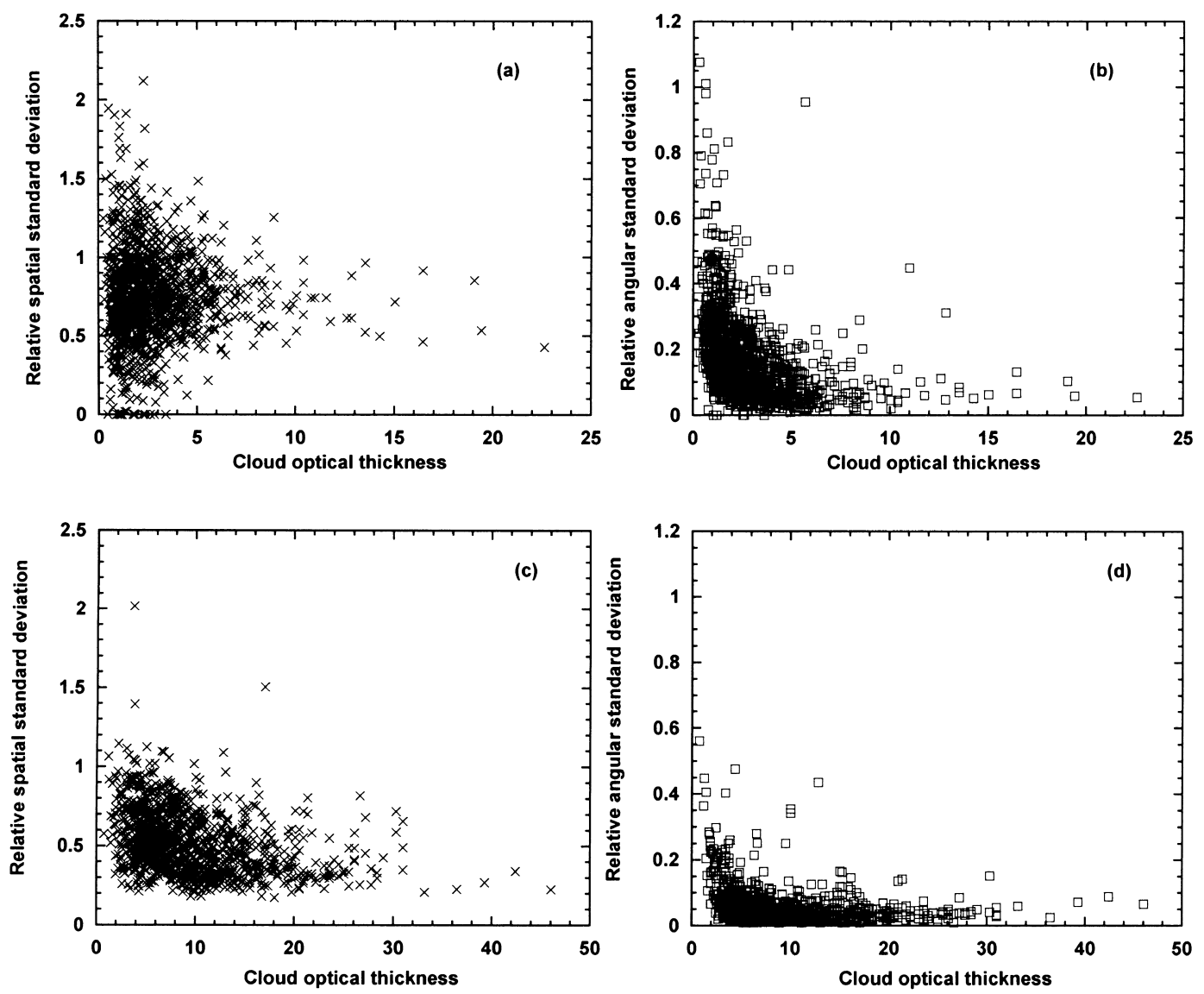

Fig. 10. (a) Relative spatial standard deviation and (b) relative angular standard deviation of cloud optical thickness versus the optical thickness for super-pixels labeled "droplets" in Fig. 9f; (a) and (b) are non-overcast super-pixels and (c) and (d) are overcast super-pixels.

thickness. Fig.10 shows that the angular dispersion is not necessarily correlated to the spatial variability, i.e., to the cloud heterogeneity.

Furthermore, the 2 relative standard deviations have been plotted as a function of the cloud cover for the cloudy pixels labeled "droplets" (Fig. 11). The variations of the 2 parameters against the cloud fractional cover are definitely different. The overall behavior of the spatial deviation can be described by an arch whereas the angular deviation varies almost linearly. Not surprisingly, the relative spatial standard deviation of cloud optical thickness is maximum for a cloud amount close to 0.5 . For overcast situations the spatial standard deviation is still high and of the same order of magnitude as for broken cloudiness conditions.
On the contrary, the relative angular deviation decreases with cloud fractional cover. For small cloud amounts, the high value of the relative angular standard deviation is indicative of the departure of these pixels from the $10 \mu \mathrm{m}$ planeparallel cloud model. This highlights the prime interest of POLDER multi-angular capability. Different cloud models could be investigated in order to minimize the retrieved angular dispersion. Further research is clearly needed. For overcast conditions the relative angular standard deviation tends to nearly zero. Although these overcast super-pixels (composed of $\sim 9 \times 9$ pixels) are not close to homogeneous clouds, they act on average as a plane-parallel model with $r_{\mathrm{e}}=10 \mu \mathrm{m}$. This extends to larger spatial scales some previous 


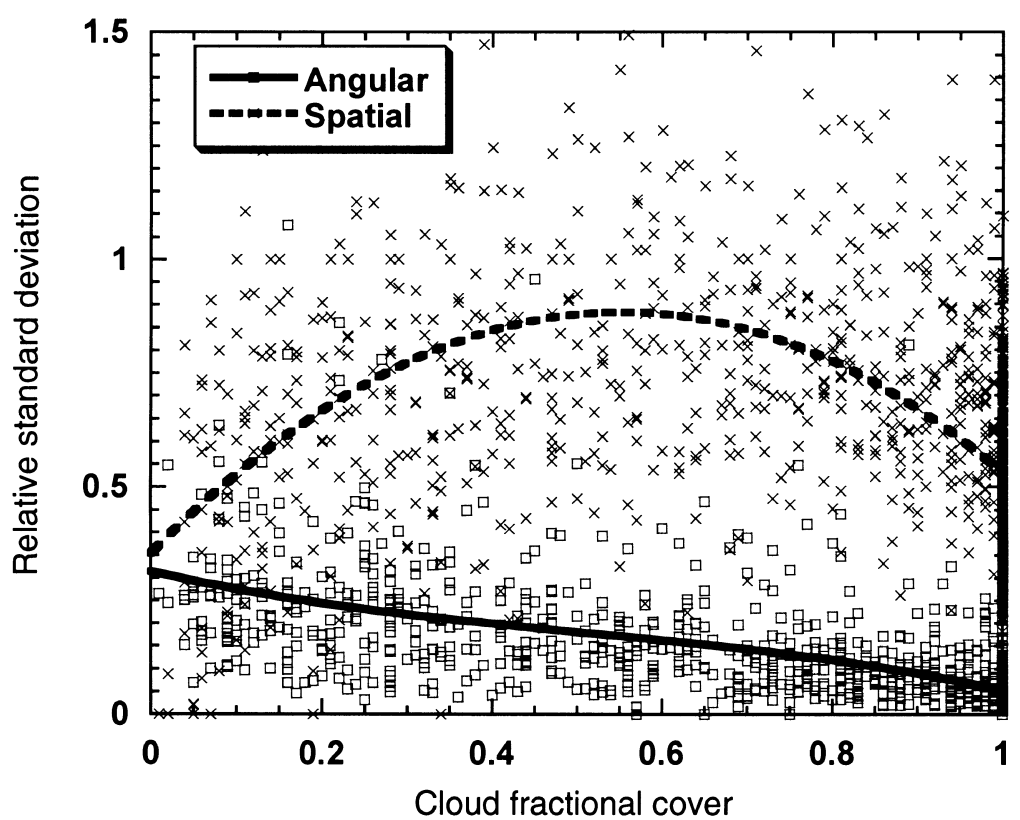

Fig. 11. Relative spatial and angular standard deviations of cloud optical thickness versus the cloud fractional cover for super-pixels labeled "droplets" in Fig. 9f. The lines are the mean curves.

results obtained using the airborne POLDER instrument (Descloitres et al., 1995, 1998). However, the suitability of the plane-parallel cloud model does not imply that the retrieved cloud optical thickness is accurate. For instance, for marine stratocumulus clouds, Cahalan (1994) found that the cloud albedo could be approximated properly by a plane-parallel model having an optical depth $30 \%$ smaller than the actual mean optical depth. In the present study, the derived cloud optical depth has to be considered as an "effective" optical depth.

\section{Conclusion}

Unlike the usual scanning radiometers, the POLDER instrument provides 10 or more quasisimultaneous reflectance measurements of any cloud scene. It is always possible to adjust a multiparameter cloud model (i.e., microphysical and macrophysical parameters) to match one single bidirectional observation of a given cloud scene. On the contrary, constraining such a model to adequately match a set of bidirectional observations is much more demanding. The multidirec- tionality of POLDER measurements is then a useful constraint for the selection of cloud parameters. POLDER allows to determine the cloud optical thickness under some hypotheses, and also enables to test the validity of these hypotheses. As mentioned in the introduction, numerous studies have derived the cloud optical thickness from space using the plane-parallel approximation and a prescribed cloud droplet size. However, up to now only few direct observations of cloud bidirectional reflectance have been compared to theoretical radiation fields calculated using the planeparallel model (see for instance Stuhlmann et al., 1985; Descloitres et al., 1998).

This paper presented results related to such comparisons within the framework of the ACE-2 Experiment. Cloud optical thickness and cloud albedo retrieved from bidirectional reflectances measured by ADEOS-POLDER and its airborne simulator were presented. First, particular attention was given to airborne POLDER data acquired on 2 golden days of the campaign 26 June and 9 July 1997. Stratocumulus clouds sampled during these 2 days had developed in air masses of different origins (Brenguier et al., 2000). 26 June corresponded to a pure marine case and July 9 
was the last day of a marine to polluted air transition. For the experimental characterization of the aerosol indirect effect, thin stratocumulus clouds had been selected in priority during ACE-2, because thin clouds are more sensitive to a change in droplet concentration. As expected for the 26 June flight mission, the cloud optical thickness values are very low, ranging typically between 1 and 5 for the leg under investigation in this paper. However, the optical thickness values retrieved on 9 July are approximately $2-3 \times$ larger.

Even though the cloud optical thickness and cloud albedo retrievals are shown to be almost not dependent on cloud droplet size in visible range channels, the multidirectional capability of POLDER is demonstrated to be very useful to select the cloud microphysical model (in terms of effective radius of droplets). The relative angular standard deviation of the retrieved parameters increases if the cloud microphysical model is inadequate. The relative angular standard deviations are more sensitive to the microphysical model as POLDER observed cloud scenes in view conditions that correspond to strong anisotropic features as the backscatter maximum and the cloudbow $\left(\sim 140^{\circ}\right.$ scattering angle). Taking advantage of this opportunity, we found that a $12 \mu \mathrm{m}$ cloud droplet size distribution was a suitable cloud model in the pure marine cloud case study (26 June). For the polluted case (9 July), the mean retrieved effective radius of droplets is of the order of $6-10 \mu \mathrm{m}$. This result can be interpreted as a confirmation of the indirect effect of aerosols. It is consistent with the significant increase in droplet concentration measured in polluted marine clouds compared to pure marine clouds (Brenguier et al., 2000). Further investigations and comparisons to in-situ microphysical measurements are needed.

The last section of this paper presented the recently validated and processed satellite POLDER data acquired along 2 ADEOS orbits on 26 June. The ACE-2 polluted cases (during the first couple of weeks of July) were not documented by ADEOS-POLDER that ended acquisition on 29 June after an unexpected failure of the platform solar panel. The main results (cloud amount, cloud optical thickness and shortwave albedo) of the "ERB \& clouds" operational algorithm were discussed for the ACE-2 region and the original contribution of POLDER regarding these properties was emphasized.

The cloud optical thickness and cloud albedo values are very low and are thus consistent with airborne POLDER retrievals. However, these low values are associated to high values of spatial and angular variability of cloud optical thickness that means to high spatial cloud macrophysical or microphysical inhomogeneity. In the "ERB \& clouds" algorithm, a cloud water droplet model with a prescribed effective radius of $10 \mu \mathrm{m}$ is used to operationally derive cloud optical thickness from ADEOS-POLDER data. Consequently, when inverting the POLDER reflectances, the optical thickness is the only cloud property that is allowed to vary. Once again, the multiangular capability of POLDER allows testing the standard cloud droplet model. Excluding the ice cloud cases for which the $10 \mu \mathrm{m}$ droplet model seems definitely inadequate (Descloitres et al., 1998; Parol et al., 1999), it appears that the angular standard deviations are not straighforwardly related to the spatial standard deviations as measured by POLDER at $\sim 56 \times 56 \mathrm{~km}^{2}$ scale. Indeed, the variations of these 2 parameters against the cloud cover are definitely different. This indicates that the departure of the observations from the bidirectional reflectance variations of the cloud model selected for the inversion is not a tracer of the 3D optical thickness distribution.

\section{Acknowledgements}

The authors are very grateful to Françoise Hennequart for her help in processing raw data of the airborne POLDER. They also gratefully acknowledge 2 anonymous referees for their very helpful comments and suggestions. This study was supported by the European Community under grant ENV4-CT95-0117, CNES, Région NordPas De Calais, and Préfecture du Nord through EFRO. Some results in this paper were obtained using CNES's POLDER onboard NASDA's ADEOS.

\section{Appendix A}

Basic formula for cloud optical thickness retrieval: droplet size effect

For a given drop size distribution $n(r)$, where $n(r)$ is the density of droplets with radius $r$ per 
unit of volume, cloud optical thickness is given by:

$\tau(\lambda)=\int_{0}^{H} \int_{0}^{\infty} Q_{\text {ext }}(x) \pi r^{2} n(r) \mathrm{d} r \mathrm{~d} h$,

where $x=2 \pi r / \lambda$ is the size parameter, and $H$ is the cloud layer geometrical thickness. The efficiency factor for extinction $Q_{\text {ext }}(2 \pi r / \lambda)$ is determined from Mie theory (Van de Hulst, 1957). $Q_{\text {ext }}(2 \pi r / \lambda)$ is a function of $r$, wavelength $\lambda$, and refractive index, $m$ (Hansen and Travis, 1974). The variation of $Q_{\text {ext }}(2 \pi r / \lambda)$ with size parameter $x$ is small particularly for large $x$ and asymptote to a value of approximately 2. This is relevant for spherical droplets of radius $r$ large compared to the wavelengths.

If the effective radius of droplet size distribution is introduced (Hansen and Travis, 1974) as:

$r_{\mathrm{e}}=\frac{\int_{0}^{\infty} \pi r^{3} n(r) \mathrm{d} r}{\int_{0}^{\infty} \pi r^{2} n(r) \mathrm{d} r}$,

and the expression of the liquid water content, $w$ $\left(\mathrm{g} \mathrm{m}^{-3}\right)$, as

$w=\int_{0}^{\infty} \frac{4}{3} \pi r^{3} \rho_{\mathrm{w}} n(r) \mathrm{d} r$,

eq. (8.1) becomes:

$\tau(\lambda)=\frac{3 \bar{Q}_{\mathrm{ext}}}{4 \rho_{\mathrm{w}}} \int_{0}^{H} \frac{w}{r_{\mathrm{e}}} \mathrm{d} h$,

where $\rho_{\mathrm{w}}$ is the liquid water density $\left(\rho_{\mathrm{w}}=\right.$ $10^{3} \mathrm{~kg} \mathrm{~m}^{-3}$ ) and $\bar{Q}_{\text {ext }}$ is the average of $Q_{\text {ext }}$ over the droplet size distribution.

The liquid water path $\operatorname{LWP}\left(\mathrm{g} \mathrm{m}^{-2}\right)$ is formally defined as:

$\mathrm{LWP}=\int_{0}^{H} w \mathrm{~d} h$.

Assuming that the cloud is vertically uniform with respect to drop-size distribution, the cloud optical thickness is linked to liquid water path and effective radius by:

$\tau(\lambda)=\frac{3 \bar{Q}_{\text {ext }}}{4 \rho_{\mathrm{w}} r_{\mathrm{e}}} \mathrm{LWP}$.

For droplets of radius $r$ large compared to the wavelength eq. (8.6) reduces to:

$\tau(\lambda) \approx \tau=\frac{3}{2} \frac{\mathrm{LWP}}{r_{\mathrm{e}}}$,

where LWP is in $\left(\mathrm{g} \mathrm{m}^{-2}\right)$ and $r_{\mathrm{e}}$ is in micrometers (Fouquart et al., 1990).

Two cloud layers have approximately the same reflection properties if they have the same values for scaled optical thickness and scaled singlescattering albedo (Van de Hulst, 1980). The similarity equation

$\tau\left(1-\tilde{\omega}_{0} g\right)=\tau^{\prime}\left(1-\tilde{\omega}_{0}^{\prime} g^{\prime}\right)$

allows us to get $\tau^{\prime}$ from $\tau$ and $r$ (the asymmetry factor $g$ and the single-scattering albedo $\tilde{\omega}_{0}$ are functions of droplet radius and wavelength; they are calculated using Mie theory and optical constants of liquid water).

The effect of drop size on cloud optical thickness retrieval from a single angular measurement of $0.865 \mu \mathrm{m}$ POLDER reflectance can be estimated from this equation. Table 1 presents the relative difference $\left(\tau^{\prime}-\tau\right) / \tau$ normalized to the cloud optical thickness retrieved assuming the $10 \mu \mathrm{m}$ effective radius. In the same way, $\left(\tau^{\prime}-\tau\right) / \tau$ represents the relative error caused by $10 \mu \mathrm{m}$ effective radius assumption used in the spaceborne POLDER operational analysis. Table 1 also lists the values of $Q_{\text {ext }}, \tilde{\omega}_{0}$, and $g$ for the different cloud droplet effective radii used in this study.

In this paper cloud optical thickness is derived from measured reflected radiance assuming the plane-parallel approximation and then it is applied to the plane-parallel model to infer the cloud albedo. From the similarity principles (Van de Hulst, 1980), the so-estimated plane-parallel albedo is not strongly dependent on drop size distribution so long as the same distribution is used in the 2 steps of the analysis.

Table 1. Effect of drop size on cloud optical thickness retrieval from a single POLDER bidirectional reflectance measurement at $0.865 \mu \mathrm{m}$

\begin{tabular}{rcclc}
\hline$r_{\mathrm{e}}(\mu \mathrm{m})$ & $Q_{\text {ext }}$ & \multicolumn{1}{c}{$\tilde{\omega}_{0}$} & \multicolumn{1}{c}{$g$} & $\left(\tau^{\prime}-\tau\right) / \tau$ \\
\hline 6 & 2.2 & 0.999970 & 0.83804 & -0.109 \\
10 & 2.1 & 0.999953 & 0.8557 & 0 \\
12 & 2.1 & 0.999943 & 0.85831 & 0.018 \\
\hline
\end{tabular}

The values of $Q_{\text {ext }}, \tilde{\omega}_{0}$, and $g$ for the different cloud droplet effective radii used in this study are also listed. 


\section{REFERENCES}

Arking, A. and Childs, J. D. 1985. Retrieval of cloud cover parameters from multispectral satellite images. J. Climate Appl. Meteor. 24, 322-333.

Baldwin, D. G. and Coakley Jr., J. A. 1991. Consistency of Earth Radiation Budget Experiment bidirectional models and the observed anisotropy of reflected sunlight. J. Geophys. Res. 96, 5195-5207.

Barsch, B. and Bakan, S. 1993. First experiences with the new array spectrometer OVID. In: ARKTIS 1993 field phase report. Ber. ZMK (ed. Bruemmer, B), Ser. A 11, 147-156.

Bréon, F.-M. 1992. Reflectance of broken cloud fields: simulation and parameterization. J. Atmos. Sci. 49 1221-1232.

Brenguier, J.L., Chuang, P. Y., Fouquart, Y., Johnson, D. W., Parol, F., Pawlowska, H., Pelon, J., Schüller, L., Schröder, F. and Snider, J. 2000. An overview of the ACE-2 CLOUDYCOLUMN closure experiment Tellus 52B, 815-827.

Brenguier, J. L., Pawlowska, H., Schüller, L., Preusker, R., Fischer, J. and Fouquart, Y. 1999. Radiative properties of boundary layer clouds: optical thickness and effective radius versus geometrical thickness and droplet concentration. J. Atmos. Sci., in press.

Brogniez, G., Parol, F., Buriez, J. C. and Fouquart, Y. 1992. Bidirectional reflectances of Cirrus clouds modelized from observations during the international cirrus experiment 89. In: Current Problems in Atmospheric Radiation, Proc. of the IRS'92, Tallin, Estonia, 3-8 August 1992, eds: S. Keevallik and O. Karner, 133-136.

Buriez, J. C., Vanbauce, C., Parol, F., Goloub, P., Herman, M., Bonnel, B., Fouquart, Y., Couvert, P. and Sèze, G. 1997. Cloud detection and derivation of cloud properties from POLDER. Int. J. Remote Sensing 13, 2785-2813.

Cahalan, R. F. 1994. Bounded cascade clouds: albedo and effective thickness. Nonlin. Proc. Geophys. 1, $156-167$.

Cahalan, R. F., Ridgway, W., Wiscombe, W. J. Gollmer, S. and Harshvardhan. 1994. Independent pixel and Monte Carlo estimates of stratocumulus albedo. J. Atmos. Sci. 51, 3776-3790.

Cess, R. D. et al. 1990. Intercomparison and interpretation of climate feedback processes in 19 atmospheric general circulation models. J. Geophys. Res. 95 $16,601-16,610$

Cess, R. D. et al. 1996. Cloud feedback in atmospheric general circulation models: an update. J. Geophys. Res. 101, 12,791-12,794.

Charlson, R. J., Schwartz, S. E., Hales, J. M., Cess, R. D., Coackley Jr., J. A., Hansen, J. E. and Hofmann, D. J. 1992. Climate forcing by anthropogenic aerosols. Science 255, 423-430.

Cox, C. and Munk, W. 1956. Slopes of the sea surface deduced from photographs of the sun glitter. Bull. of the Scripps Institute of Oceanography 6, 401-488.

Davis, J. M. and Cox, S. K. 1982. Reflected solar radiances from regional scale scenes. J. Appl. Meteor. 21, $1698-1712$

Deschamps, P. Y., Bréon, F. M., Leroy, M., Podaire, A., Bricaud, A., Buriez, J. C. and Sèze, G. 1994. The POLDER mission: instrument characteristics and scientific objectives. IEEE Trans. Geosci. Remote Sensing 32, 598-615.

Descloitres, J., Parol, F. and Buriez, J. C. 1995. On the validity of the plane-parallel approximation for cloud reflectances as measured from POLDER during ASTEX. Ann. Geophysicae 13, 108-110.

Descloitres, J., Pawlowska, H., Pelon, J., Brenguier, J. L., Parol, F., Buriez, J. C. and Flamant, P. 1996. Experimental retrieval of cloud optical thickness during EUCREX: comparison of three approaches. Proc. of the 12th International Conference on Clouds and precipitation. Zurich, Switzerland. Page Bros. (Norwich), pp. 394-397.

Descloitres, J., Buriez, J. C., Parol, F. and Fouquart, Y. 1998. POLDER observations of cloud bidirectional reflectances compared to a plane-parallel model using the ISCCP cloud phase functions. J. Geophys. Res. 103, 11,411-11,418.

Diner, D. J., Beckert, J. C., Reilly, T. H., Bruegge, C. J., Conel, J. E., Kahn, R., Martonchik, J. V., Ackerman, T. P., Davies, R., Gerstl, S. A. W., Gordon, H. R., Muller, J.-P., Myneni, R., Sellers, R. J., Pinty, B. and Verstraete, M. M. 1998. Multiangle Imaging SpectroRadiometer (MISR) description and experiment overview. IEEE Trans. Geosci. Rem. Sens. 36, 1072-1087.

Fouquart, Y., Buriez, J. C., Herman, M. and Kandel, R. S. 1990. The influence of clouds on radiation: a climate-modelling perspective. Rev. of Geophys. 28, 145-166.

Hagolle, O., Goloub, P., Deschamps, P.-Y., Cosnefroy, H., Briottet, X., Bailleul, T., Nicolas, J.-M., Parol, F., Lafrance, B. and Herman, M. 1999. Results of POLDER in-flight calibration. IEEE Trans. Geosci. Remote Sensing 37, 1550-1567.

Han, Q., Rossow, W. B. and Lacis, A. A. 1994. Nearglobal survey of effective droplet radii in liquid water clouds using ISCCP data. J. Climate 7, 465-497.

Hansen, J. E. 1971. Multiple scattering of polarized light in planetary atmospheres. Part II: sunlight reflected by terrestrial water clouds. J. Atmos. Sci. 28, 1400-1426.

Hansen, J. E. and Travis, L. D. 1974. Light scattering in planetary atmospheres. Space Sci. Rev. 16, 527-610.

Harrison, E. F., Minnis, P., Barkstrom, B. R., Ramanathan, V., Cess, R. D. and Gibson, G. G. 1990. Seasonal variations of cloud radiative forcing derived from the Earth Radiation Budget Experiment. J. Geophys. Res. 95, 18,687-18,703.

Tellus 52B (2000), 2 
Houghton, J. T., Jenkins, G. J. and Ephraums, J. J. (eds.). 1990. Climate change: the IPCC scientific assessment World Meteorological Organization/United Nations Environment Programme, Cambridge University Press, 364 pp.

Kandel, R. S., Monge, J. L., Viollier, M., Pakhomov, L. A., Adasko, V. I., Reitenbach, R. G., Raschke, E and Stuhlmann, R. 1994. The ScaRaB project: Earth radiation budget observations from the Meteor satellites, World Space Congress (Washington)-COSPAR symp. A.2-S. Adv. Space Research 14(1), 47-54.

King, M. D., Kaufman, Y. J., Menzel, W. P. and Tanré, D. 1992. Remote sensing of cloud, aerosol, and water vapor properties from the moderate resolution imaging spectrometer (MODIS). IEEE Trans. Geosci. Rem. Sens. 30, 2-27.

Kobayashi, T. 1993. Effects due to cloud geometry on biases in the aldebo derived from radiance measurements. J. Climate 6, 120-128.

Leroy, M., Deuze, J. L., Breon, F. M., Hautecoeur, O., Herman, M., Buriez, J. C., Tanre, D., Bouffies, S., Chazette, P. and Roujean, J. L. 1997. Retrieval of atmospheric properties and surface bidirectional reflectances over the land from POLDER/ADEOS J. Geophys. Res. 102, 17,023-17,037.

Loeb, N. G., Varnai, T. and Davies, R. 1997. The effect of cloud inhomogeneities on the solar zenith angle dependence of nadir reflectance. J. Geophys. Res. 102 9387-9395

Loeb, N. G. and Coakley Jr., J. A. 1998. Inference of marine stratus cloud optical depths from satellite measurements: does 1D theory apply? J. Climate $\mathbf{1 1}$ 215-233.

Mishchenko, M. I., Rossow, W. B., Macke, A. and Lacis, A. A. 1996. Sensitivity of cirrus cloud albedo, bidirectional reflectance and optical thickness retrieval accuracy to ice particle shape. J. Geophys. Res. 101, $16,973-16,985$.

Nakajima, T. and King, M. D. 1990. Determination of the optical thickness and effective particle radius of clouds from reflected solar radiation measurements. Part I: theory. J. Atmos. Sci. 47, 1878-1893.

Nakajima, T., King, M. D., Spinhirne, J. D. and Radke, L. F. 1991. Determination of the optical thickness and effective particle radius of clouds from reflected solar radiation measurements. Part II: marine stratocumulus observations. J. Atmos. Sci. 48, 728-750.

Parol, F., Buriez, J. C., Crétel, D. and Fouquart, Y. 1994. The impact of cloud inhomogeneities on the Earth radiation budget: The 14 October 1989 ICE convective cloud case study. Ann. Geophysicae 12, 240-253.

Parol, F., Buriez, J. C., Vanbauce, C., Couvert, P. Sèze, G., Goloub, P. and Cheinet, S. 1999. First results of the POLDER "Earth Radiation Budget and Clouds" operational algorithm, IEEE Trans. Geosci. Rem. Sens. 37, 1597-1612.

Pawlowska, H., Brenguier, J. L., Fouquart, Y., Armbruster, W., Descloitres, J., Fischer, J., Flamant, C., Fouilloux, A., Gayet, J. F., Ghosh, S., Jonas, P., Parol, F.,
Pelon, J. and Schüller, L. 1999. Microphysical and radiative properties of stratocumulus clouds. The EUCREX mission 206 case study. Atmos. Res., in press.

Raes, F., Bates, T., McGovern, F. and Van Liedekerke, M. 2000. The second Aerosol Chatacterization Experiment (ACE-2): general context and main results. Tellus 52B, 111-126.

Ramanathan, V., Cess, R. D., Harrison, E. F., Minnis, P. Barkstrom, B. R., Ahmad, E. and Hartmann, D. 1989. Cloud radiative forcing and climate: results from the earth radiation budget experiment. Science 243, 57-63.

Rossow, W. B. and Schiffer, R. A. 1991. ISCCP cloud data products. Bull. Amer. Meteor. Soc. 72, 2-20.

Senior, C. A. and Mitchell, J. F. B. 1993. Carbon dioxide and climate. The impact of cloud parameterisation. J. Climate 6, 393-418.

Slingo, A., Nicholls, S. and Schmetz, J. 1982. Aircraft observations of marine stratocumulus during JASIN. Quart. J. Roy. Meteor. Soc. 108, 833-856.

Spinhirne, J. D., Hart, W. D. and Hlavka, D. L. 1996. Cirrus infrared parameters and short-wave reflectance relations from observations. J. Atmos. Sci. 53, 1438-1458.

Stamnes, K., Tsay, S. C., Wiscombe, W. and Jayaweera, W. 1988. Numerically stable algorithm for discrete-ordinate-method radiative transfer in multiple scattering and emitting layered media. Appl. Opt. 27, 2502-2509.

Stephens, G. L. 1978. Radiation profiles in extended water clouds. II: parameterization schemes. J. Atmos. Sci. 35, 2123-2132.

Stephens, G. L. and Platt, C. R. M. 1987. Aircraft observations of the radiative and microphysical properties of stratocumulus and cumulus cloud fields. J. Climate Appl. Meteor. 26, 1243-1269.

Stuhlmann, R., Minnis, P. and Smith, G. L. 1985. Cloud bidirectional reflectance functions: a comparison of experimental and theoretical results. Appl. Opt. 24, 396-401.

Vanbauce, C., Buriez, J. C., Parol, F., Bonnel, B., Sèze, G. and Couvert, P. 1998. Apparent pressure derived from ADEOS-POLDER observations in the oxygen A-band over ocean. Geophys. Res. Lett. 25, 3159-3162.

Van de Hulst, H. C. 1957. Light scattering by small particles. John Wiley and Sons, New York, 470 pp.

Van de Hulst, H. C. 1980. Multiple light scattering, tables, formulas, and applications, vol. 1. Academic Press, 739 pp.

Verver, G., Raes, F., Vogelezang, D. and Johnson, D 2000. The second Aerosol Characterization Experiment (ACE-2): meteorological and chemical context. Tellus 52B, 126-140.

Wielicki, B. A. and Barkstrom, B. R. 1991. Cloud and the earth's radiant energy system (CERES): an earth observing system experiment. Second Symp. on Global change studies. New Orleans, LA, Amer. Meteor. Soc., pp. 11-16. 